\title{
The CCAPM with Varying Preferences
}

\author{
Samih Antoine Azar ${ }^{1}$ \\ ${ }^{1}$ Faculty of Business Administration \& Economics, Haigazian University, Lebanon \\ Correspondence: Samih Antoine Azar, Faculty of Business Administration \& Economics, Haigazian University, \\ Mexique Street, Kantari, Beirut, Lebanon. Tel: 961-346-8697. E-mail: samih.azar@haigazian.edu.lb
}

Received: November 8, 2016

Accepted: January 20, 2017

Online Published: January 26, 2017

doi:10.5539/ijbm.v12n2p199

URL: http://dx.doi.org/10.5539/ijbm.v12n2p199

\begin{abstract}
The Consumption Capital Asset Pricing Model (CCAPM) is by now a paradigm in financial economics. Applied to the risk-free rate, the CCAPM implies an Euler equation which depends on expected marginal utilities. The paper uses a widespread functional form to specify the utility. However the paper introduces varying preferences into the Euler equation. This enables us to find a relation between the current risk-free rate and the current level of real per capita consumption. Empirically this relation finds that risk aversion is lower for the short run and higher for the long run. The difference between the two is economically small but it is still statistically significant. The paper calculates the differential risk premium required to compensate for the higher long run risk aversion. This premium is also economically small. The paper concludes that the evidence supports that, in the long run, risk is either the same or higher than the short run risk.
\end{abstract}

Keywords: CCAPM, consumption, risk-free rate, Euler equation, varying preferences, coefficient of relative risk aversion, ARDL estimation, cointegration, error-correction models, risk aversion, short run and long run

JEL Codes: G12, D81, C22, C12.

\section{Introduction}

The Consumption Capital Asset Pricing Model (CCAPM) is based on the following classic system of equations, where $E$ is the expectation operator for the present time, or for the current information set, $C$ is real per capita consumption, $U(C)$ is the utility function with its main argument $C, \beta$ is the constant discount rate of time preference, and $t$ is the time period (Campbell \& Viciera, 2002; Danthine \& Donaldson, 2015):

$$
\text { maximize } E_{t} \sum_{t=0}^{\infty} \beta^{t} U_{t}\left(C_{t}\right)
$$

This function is subject to one of the below asset evolution equations, where $A$ is non-human financial wealth, $Y$ is human or labor income, and $r_{t}$ is the time-dependent risk-free interest rate:

$$
\begin{aligned}
A_{t+1} & =\left(1+r_{t}\right)\left(A_{t}+Y_{t}-C_{t}\right) \\
\text { Or } \quad A_{t+1} & =\left(1+r_{t}\right) A_{t}+Y_{t}-C_{t}
\end{aligned}
$$

It is understood that the two asset evolution equations (2) and (3) produce the same first-order Euler condition (Azar, 2012). If $\partial(U(C)) / \partial(C)$ is the marginal utility of the only argument of the utility function inside the parentheses $C$, this Euler first-order condition becomes:

$$
\beta\left(1+r_{t}\right) E_{t}\left(\frac{\partial\left(U_{t+1}\right) / \partial\left(C_{t+1}\right)}{\partial\left(U_{t}\right) / \partial\left(C_{t}\right)}\right)=1
$$

When $\gamma$ is defined to be the constant coefficient of relative risk aversion, the utility function becomes as is commonly specified:

$$
U_{t}\left(C_{t}\right)=\frac{C_{t}^{1-\gamma}-1}{1-\gamma}
$$

Equation (5) implies that the marginal utility of $C_{t}$ is equal to $C_{t}^{-\gamma}$, which in turn implies that equation (4) now becomes:

$$
\beta\left(1+r_{t}\right) E_{t}\left(\frac{C_{t}}{c_{t+1}}\right)^{\gamma}=1
$$


This paper will assume that the utilities differ in regard to the coefficient of risk aversion, implying varying preferences. If one is willing to assume that risk aversion is not the same, then the utility functions can be rewritten as follows (with $\alpha$ defined as a positive number):

$$
E_{t}\left(U_{t}\right)=U_{t}=\frac{c_{t}^{1-\gamma+\alpha}-1}{1-\gamma} \text { and } E_{t}\left(U_{t+\tau}\right)=E_{t}\left(\frac{c_{t+\tau}^{1-\gamma}-1}{1-\gamma}\right)
$$

Using equations (7), equation (6) will therefore be equal to the following two equations:

$$
\beta\left(1+r_{t}\right) E_{t}\left(\frac{c_{t}^{\gamma-\alpha}}{c_{t+1}^{\gamma}}\right)=1 \text { or } \beta\left(1+r_{t}\right) C_{t}^{-\alpha} E_{t}\left(\frac{C_{t}}{c_{t+1}}\right)^{\gamma}=1
$$

The last term of the second equation in (8) can be rewritten as:

$$
E_{t}\left(\frac{c_{t}}{c_{t+1}}\right)^{\gamma}=E_{t} \exp \left(\gamma \ln \left(\frac{c_{t}}{c_{t+1}}\right)\right)=E_{t} \exp \left(-\gamma \ln \left(\frac{c_{t+1}}{c_{t}}\right)\right)
$$

If the log of the ratio of contiguous consumption levels is log-normally distributed, then, by replacing equation (9) in equations (8) one obtains the following, with $\sigma_{c}^{2}$ being the variance of the log of the ratio of the two contiguous consumption levels:

$$
\beta\left(1+r_{t}\right) C_{t}^{-\alpha} \exp \left(-\gamma E_{t}\left(\ln \left(\frac{c_{t+1}}{c_{t}}\right)\right)+0.5 \gamma^{2} \sigma_{c}^{2}\right)=1
$$

Replace the following average into equation (10):

$$
\bar{g}=E_{t}\left(\ln \left(\frac{C_{t+1}}{C_{t}}\right)\right)
$$

then take logs on both sides of equation (10), and by rearranging, one gets:

$$
\ln \left(1+r_{t}\right)=-\ln (\beta)+\alpha \ln \left(C_{t}\right)+\gamma \bar{g}-0.5 \gamma^{2} \sigma_{c}^{2}=\text { constant }+\alpha \ln \left(C_{t}\right)
$$

Equation (11), converted into a simple linear regression, is the equation that will be put to the test in the following section.

The paper is structured as follows. The second section provides the estimation results of equation (11). The third section analyses the implications of the empirical results. And the final section summarizes and concludes.

\section{The Empirical Results}

The econometric procedure is a two-step one. At first the cointegration regression is identified and estimated. Then the cointegration residual is retrieved. Finally the error-correction model, with the first lag of the cointegration residual, and with an IGARCH specification of the conditional variance, is estimated. The error-correction model (ECM) is selected from the estimation by the Autoregressive Distributed Lag model (ARDL). The ARDL procedure has two advantages: it accommodates both stationary and non-stationary variables, and it does not impose the same lag length on all the variables.

The first cointegration regression is just by Ordinary Least Squares (OLS). The coefficient estimates from OLS are unbiased despite the highly auto-correlated residuals. The next three cointegration regressions are estimated by the Fully-Modified OLS (FMOLS) (Phillips \& Hansen, 1990; Hansen, 1992a, 1992b), the Dynamic OLS (DOLS) (Saikkonen, 1992; Stock \& Watson, 1993), and the Canonical Cointegrating Regression (CCR) (Park, 1992), where OLS in the denominations above stands for Ordinary Least Squares. The fifth one is the Auto-Regressive Distributed Lag Model (ARDL) (Pesaran \& Shin, 1999; Pesaran et al., 2001), which identifies the vector error correction model (ECM) as mentioned above. At the end the five ECMs are estimated, with the five different lagged cointegration residuals, and with an IGARCH specification of the conditional variance. All computations are carried out with the EViews 9.5 statistical package.

A requirement for cointegration is that the variables should be of the same order of integration. Three unit root tests are applied: the Augmented Dickey-Fuller test (Dickey \& Fuller, 1979, 1981), the Phillips-Perron test (Phillips \& Perron, 1988), and the Elliott-Rothenberg-Stock point-optimal test (Elliott et al., 1996). The variables of interest are defined by equation (11). The first variable is the log of one plus the quarterly one-year T-bill rate in the secondary market. The second variable is the log of real per capita consumption expenditures. Both variables are with a quarterly frequency, and are retrieved from the web site of the Federal Reserve Bank of Saint Louis.

The unit root tests are conducted with a constant and a trend. The lag length for the unit root tests and for all the 
tests throughout this paper, like the ARDL, is based on minimizing the Schwarz information criterion. Unit root tests are sensitive to the lag length. However none of the lag lengths is close to the maximum allowed lag length of 15 . Table 1 presents the results. Unit roots in the log-levels of the variables fail to be rejected at high marginal confidence levels. Inspection of the first-differences of the variables rejects the null hypothesis of unit root at low marginal significance levels. The only discrepancy is the Elliott-Rothenberg-Stock point-optimal test on the first difference of the log of real per capita consumption expenditures which produces a rejection of the null of non-stationarity with a marginal significance level between $1 \%$ and $5 \%$. Based on all these tests it is concluded that the two variables have both one and only one unit root.

Table 1. Unit root tests

\begin{tabular}{|c|c|c|c|c|c|c|}
\hline \multirow{2}{*}{$\begin{array}{l}\text { variable } \\
\text { X }\end{array}$} & \multicolumn{2}{|l|}{ ADF tests } & \multicolumn{2}{|c|}{ Phillips \& Perron tests } & \multicolumn{2}{|c|}{$\begin{array}{l}\text { Elliott-Rothenberg-Stock } \\
\text { point-optimal tests }\end{array}$} \\
\hline & $\log X$ & $\Delta \log \mathrm{X}$ & $\log X$ & $\Delta \log \mathrm{X}$ & $\log X$ & $\Delta \log X$ \\
\hline $\begin{array}{l}\text { One plus one-year T-Bill secondary } \\
\text { market rate (TB) }\end{array}$ & $\begin{array}{l}0.0711 \\
{[3]}\end{array}$ & $\begin{array}{l}0.0000 \\
{[2]}\end{array}$ & 0.1695 & 0.0000 & $\begin{array}{l}>10 \% \\
{[3]}\end{array}$ & $\begin{array}{l}<1 \% \\
{[2]}\end{array}$ \\
\hline $\begin{array}{l}\text { Real per capita consumption expenditures } \\
\text { (RCCE) }\end{array}$ & $0.3262[3]$ & $0.0007[2]$ & 0.7683 & 0.0000 & $\begin{array}{l}>10 \% \\
{[3]}\end{array}$ & $\begin{array}{l}\text { Between } 1 \% \text { and } \\
5 \%[2]\end{array}$ \\
\hline
\end{tabular}

Notes. The tests are with a constant and a trend. The null hypotheses are for the existence of a unit root. Actual p-values are reported. In brackets are lag lengths. The lag length is selected by the Schwarz information criterion. The sample size is quarterly from Q1 1971 to Q2 2016.

Table 2 presents the cointegration regressions. The sign of the coefficient on $\alpha$, (see equation (11)), is negative and not positive. This coefficient is statistically significantly different from zero at very low marginal significance levels. The minimum absolute t-statistic is 2.7255 , and has a two-tailed p-value of 0.0070 . The negative coefficient ranges from a low of -0.024807 (FMOLS) to a high of -0.022841 (OLS). Therefore the coefficient of relative risk aversion is higher in the long run. This means that investors have less appetite for risk in the long run, and they are willing to take only lower risks. In other terms the results predict that the long run risk is lower than the short run risk for the same rate of return. One should not jump to the conclusion that the difference in risk aversion, though statistically significant, is large. In fact economically this difference is rather small in magnitude. If the coefficient of relative risk aversion is assumed to be 3 the difference of 0.023 amounts to only a $0.767 \%$ change.

Table 2. Cointegration regressions

\begin{tabular}{|c|c|c|c|c|c|c|}
\hline & $\begin{array}{l}\text { Ordinary Least } \\
\text { Squares (OLS) }\end{array}$ & $\begin{array}{l}\text { ARDL long run } \\
\text { specification }\end{array}$ & $\begin{array}{l}\text { Canonical Cointegrating } \\
\text { Regression }(\mathrm{CCR})\end{array}$ & $\begin{array}{l}\text { Dynamic Least } \\
\text { Squares } \\
\text { (DOLS) }\end{array}$ & $\begin{array}{l}\text { Fully-Modified } \\
\text { Squares (FMOLS) }\end{array}$ & Least \\
\hline \multirow[t]{3}{*}{ Constant } & 0.243312 & 0.248150 & 0.261400 & 0.246436 & 0.255480 & \\
\hline & (15.19833) & $(3.089471)$ & (3.106290) & (7.217137) & $(2.856720)$ & \\
\hline & {$[0.0000]$} & {$[0.0023]$} & {$[0.0022]$} & {$[0.0000]$} & {$[0.0048]$} & \\
\hline Slope on & -0.022841 & -0.023856 & -0.024807 & -0.023103 & -0.024211 & \\
\hline \multirow[t]{2}{*}{$\log$ RCCE } & (14.36371) & $(3.005101)$ & $(2.955864)$ & $(6.829683)$ & $(2.725462)$ & \\
\hline & {$[0.0000]$} & {$[0.0030]$} & {$[0.0035]$} & {$[0.0000]$} & {$[0.0070]$} & \\
\hline Adjusted & 0.526025 & - & 0.485127 & 0.528690 & 0.490573 & \\
\hline \multicolumn{7}{|l|}{ R-Square } \\
\hline $\begin{array}{l}\text { Definition of } \\
\text { the residual }\end{array}$ & RESOLS & RESARDL & RESCCR & RESDOLS & RESFMOLS & \\
\hline
\end{tabular}

Notes. The dependent variable is the log of one plus the one year T-Bill secondary market rate $(\log (1+\mathrm{TB}))$ where TB is the one-year percentage rate divided by 400 . The independent variable is the log of real per capita consumption expenditures (log RCCE). Absolute t-statistics are in parentheses. In brackets are actual two-tailed p-values.

Table 3 presents the estimated vector ECM models. All five equations have the same independent variables except for the lagged cointegration residual that is retrieved from the cointegration equations in Table 2 . The 
coefficient on the change in the log of RCCE (real per capita consumption expenditures) varies between a maximum of 0.040122 with a t-statistic of 2.9698 and a two-tailed p-value of 0.0030 (with CCR), to a minimum of 0.036407 with a t-statistic of 2.7609 , and a two-tailed p-value of 0.0058 (with OLS). Hence risk aversion is lower in the short run, the appetite for risk is higher, and investors are willing to take more risks. For the same return the actual short run risk that is borne is higher. But again, relatively speaking, the difference is not that economically large, standing for about $0.7 \%$ of the size of the coefficient of relative risk aversion assumed to be 5. However the difference in risk aversion from the short run to the long run is higher at $1.33 \%$, for the same assumed coefficient of risk aversion of 3 .

Table 3. Error-correction models (ECM) with an IGARCH conditional variance equation

\begin{tabular}{|c|c|c|c|c|c|}
\hline Definition of the cointegration residual & RESOLS & RESARDL & RESCCR & RESDOLS & RESFMOLS \\
\hline \multirow[t]{3}{*}{ Constant } & -0.000320 & 0.00000636 & -0.000168 & -0.000322 & -0.000186 \\
\hline & $(4.785096)$ & $(0.779344)$ & $(2.422456)$ & $(4.701670)$ & $(2.718444)$ \\
\hline & {$[0.0000]$} & {$[0.4358]$} & {$[0.0154]$} & {$[0.0000]$} & {$[0.0066]$} \\
\hline Slope on & 0.036407 & 0.036574 & 0.036651 & 0.040122 & 0.036611 \\
\hline \multirow[t]{2}{*}{$\Delta \log \mathrm{RCCE}$} & $(2.760866)$ & $(2.728671)$ & $(2.705441)$ & $(2.969813)$ & $(2.719262)$ \\
\hline & {$[0.0058]$} & {$[0.0064]$} & {$[0.0068]$} & {$[0.0030]$} & {$[0.0065]$} \\
\hline \multicolumn{6}{|l|}{ Slopes on: } \\
\hline $1^{\text {st }}$ lag of & 0.426111 & 0.424455 & 0.423185 & 0.431840 & 0.423949 \\
\hline \multirow[t]{2}{*}{$\Delta \log (1+\mathrm{TB})$} & $(6.369509)$ & $(6.334497)$ & $(6.302142)$ & $(6.447701)$ & $(6.322296)$ \\
\hline & {$[0.0000]$} & {$[0.0000]$} & {$[0.0000]$} & {$[0.0000]$} & {$[0.0000]$} \\
\hline $2^{\text {nd }}$ lag of & -0.227870 & -0.223901 & -0.220433 & -0.232426 & -0.222576 \\
\hline \multirow[t]{2}{*}{$\Delta \log (1+\mathrm{TB})$} & $(2.978615)$ & $(2.880460)$ & $(2.798500)$ & $(2.966889)$ & $(2.848750)$ \\
\hline & {$[0.0029]$} & {$[0.0040]$} & {$[0.0051]$} & {$[0.0030]$} & {$[0.0044]$} \\
\hline $3^{\text {rd }}$ lag of & 0.311745 & 0.314503 & 0.317098 & 0.316558 & 0.315472 \\
\hline \multirow[t]{2}{*}{$\Delta \log (1+\mathrm{TB})$} & $(4.117339)$ & $(4.111423)$ & $(4.116248)$ & $(4.153032)$ & $(4.112161)$ \\
\hline & {$[0.0000]$} & {$[0.0000]$} & {$[0.0000]$} & {$[0.0000]$} & {$[0.0000]$} \\
\hline First lag of the cointegration residual & -0.066961 & -0.068286 & -0.069450 & -0.061839 & -0.068729 \\
\hline \multirow[t]{2}{*}{ (see top row) } & (7.198343) & $(7.053786)$ & $(6.915394)$ & $(6.467757)$ & $(7.002559)$ \\
\hline & {$[0.0000]$} & {$[0.0000]$} & {$[0.0000]$} & {$[0.0000]$} & {$[0.0000]$} \\
\hline \multirow[t]{4}{*}{$\operatorname{ARCH}(1)$} & 0.167085 & 0.160502 & 0.155319 & 0.160775 & 0.158457 \\
\hline & $(6.966314)$ & (7.141988) & $(7.319264)$ & (7.151937) & $(7.208388)$ \\
\hline & {$[0.0000]$} & {$[0.0000]$} & {$[0.0000]$} & {$[0.0000]$} & {$[0.0000]$} \\
\hline & 0.832915 & 0.839498 & 0.844681 & 0.839225 & 0.841543 \\
\hline \multirow[t]{2}{*}{ GARCH(1) } & $(34.72697)$ & $(37.35586)$ & $(39.80492)$ & $(37.33226)$ & $(38.28282)$ \\
\hline & {$[0.0000]$} & {$[0.0000]$} & {$[0.0000]$} & {$[0.0000]$} & {$[0.0000]$} \\
\hline \multirow[t]{3}{*}{ Speed of adjustment to the long run (in quarters) } & 14.93412 & 14.64434 & 14.39886 & 16.17105 & 14.54995 \\
\hline & (7.198343) & (7.053786) & $(6.915394)$ & $(6.467757)$ & (7.002559) \\
\hline & {$[0.0000]$} & {$[0.0000]$} & {$[0.0000]$} & {$[0.0000]$} & {$[0.0000]$} \\
\hline Adjusted R-Square & 0.210960 & 0.212242 & 0.213016 & 0.208847 & 0.212580 \\
\hline Akaike inf. criterion & -10.49989 & -10.49964 & -10.49930 & -10.48742 & -10.49953 \\
\hline Schwarz inf. criterion & -10.37666 & -10.37641 & -10.37607 & -10.36419 & -10.37630 \\
\hline$Q(4)$ & 0.715 & 0.770 & 0.811 & 0.849 & 0.787 \\
\hline$Q(8)$ & 0.507 & 0.535 & 0.556 & 0.548 & 0.544 \\
\hline$Q(12)$ & 0.797 & 0.819 & 0.835 & 0.825 & 0.825 \\
\hline $\mathbf{Q}^{2}(\mathbf{4})$ & 0.101 & 0.074 & 0.056 & 0.092 & 0.067 \\
\hline$Q^{2}(8)$ & 0.305 & 0.242 & 0.194 & 0.284 & 0.223 \\
\hline$Q^{2}(12)$ & 0.476 & 0.409 & 0.353 & 0.461 & 0.388 \\
\hline Normality & 0.000000 & 0.000000 & 0.000000 & 0.000000 & 0.000000 \\
\hline
\end{tabular}

Notes. The definitions of the cointegration residuals in each equation are taken from Table 2. Absolute t-statistics are in parentheses. Actual two-tailed p-values are in brackets. $\mathrm{Q}(\mathrm{k})$ is the Ljung-Box Q-statistic for lag length $\mathrm{k}$ on the standardized residuals. $\mathrm{Q}^{2}(\mathrm{k})$ is the Ljung-Box $\mathrm{Q}$-statistic for lag length $\mathrm{k}$ on the squared standardized residuals. Actual p-values are reported for the Q-statistic and the $\mathrm{Q}^{2}$-statistics. Actual p-values are reported for the Jarque-Bera normality tests on the standardized residuals. 
The coefficient on the lagged residual varies from a low of -0.069450 with an absolute t-statistic of 6.9154 , and a two-tailed p-value of 0.0000 (DOLS) to a high of -0.061839 , with an absolute t-statistic of 6.4678 and a two-tailed p-value of 0.0000 (FMOLS). Therefore this error-correction variable is very highly statistically significant, which implies indirectly that the cointegration regressions are appropriate ones.

The adjustment to the long run stands at a maximum of 16.1710 quarters (t-statistic: 6.4677) with a DOLs estimation, to a minimum number of 14.3989 quarters (t-statistic: 6.91539) with a CCR estimation. Hence it takes around 4 years to reach long run equilibrium.

Is there a way to choose among the five ECM models? As a matter of fact since the dependent variable is the same, a choice can be made by comparing the Akaike and the Schwarz information criteria across the ECM regressions. Both of these reach their minima for the ECM with the OLS cointegration residual. Therefore the ECM based on the OLS cointegration residuals is to be preferred to the other four (column 2, Table 3). The adjustment to the long run of this preferred vector ECM takes 14.9341 quarters.

Finally the Q-statistics and the $\mathrm{Q}^{2}$-statistics find no higher-order serial correlation and no higher-order conditional heteroscedasticity in the standardized residuals, although normality of these standardized residuals is rejected at very low marginal significance levels.

\section{Analysis of the Results}

It would be interesting to assess the impact of the change in preferences on the required rate of return of investors. For example, in the beta/(expected return) space higher risk aversion is translated by a counterclockwise rotation of the Security Market Line around the y-intercept which has as coordinates a zero beta and the size of the risk-free rate of return (Brigham and Houston, 2013). In simple words, when risk aversion is higher, investors require a higher expected return for the same risk, or a lower risk for the same expected return. However the combination of the two required changes in risk and return is uncertain. Fortunately there is a way around this problem, at least in what concerns the ultimate change in the required rate of return. The method adopted is based on Azar (2006). This method consists of depicting a discrete distribution for the risky return, assuming that the certainty equivalent utility is that of the risk-free rate, and factoring out initial wealth. The underlying relation is a generalization of the following:

$$
U[W(1+r f)]=E[U(W(1+\tilde{r}))] \Rightarrow U(1+r f)=E[U(1+\tilde{r})]
$$

where we assume the same functional form for the utility as in equation (5), where $r f$ is the risk-free rate, where $\tilde{r}$ is the risky return, where $E$ is the expectation operator on the current information set, and where $W$ is initial wealth that cancels out. Equation (12) can be rewritten as the following, using the functional form in equation (5), with discrete data of $n$ outcomes, each with probability $\pi_{i}$, and after some manipulation and simplification:

$$
\sum_{i=1}^{n} \pi_{i}(1+\tilde{r})^{1-\gamma}=(1+r f)^{1-\gamma}
$$

In Ross et al. (2002) the arithmetic average, over the period 1926 to 1999, of a portfolio of common stocks is $13.3 \%$ with an annual standard deviation of $20.1 \%$, while the risk-free rate, measured by the T-bill yield, averaged 3.8\% per annum. These are the parameters adopted in Azar (2006) for whom one economy, found in Panel $\mathrm{F}$ of Table 1, is portrayed to have the following seven equally probable outcomes: $55 \%, 35 \%, 15 \%, 10 \%$, $0 \%,-5 \%,-15 \%$. These seven outcomes describe a distribution with mean $13.57 \%$ and a standard deviation of $22.73 \%$, quite close to the parameters of Ross et al. (2002).

The first step is to identify the basic coefficient of relative risk aversion which is carried out by using the Solver command of Excel by varying $\gamma$ to set the following relation to zero:

$$
1.038^{1-\gamma}-(1 / 7)\left(1.55^{1-\gamma}+1.35^{1-\gamma}+1.15^{1-\gamma}+1.10^{1-\gamma}+1^{1-\gamma}+0.95^{1-\gamma}+0.85^{1-\gamma}\right)=0
$$

Solver finds a solution which is $\gamma=5.49518$.

The second step is to assume a constant premium $\theta$ to be added to each outcome so that the new coefficient of relative risk aversion is higher by 0.06 , which is the change in risk aversion obtained previously, and then to apply the solver command to find this premium:

$$
\begin{aligned}
& 1.038^{1-5.495179-0.06} \\
& -(1 / 7)\left([1.55+\theta]^{1-5.459179-0.06}+[1.35+\theta]^{1-5.495179-0.06}+[1.15+\theta]^{1-5.495179-0.06}\right. \\
& +[1.10+\theta]^{1-5.495179-0.06}+[1+\theta]^{1-5.495179-0.06}+[0.95+\theta]^{1-5.495179-0.06} \\
& \left.+[0.85+\theta]^{1-5.495179-0.06}\right)=0
\end{aligned}
$$

The solver command finds the optimal solution to be $\theta=0.000756$, or 7.56 basis points, which is $0.557 \%$ of 
the average return of the risky portfolio of stocks.

Since the computations may be sensitive to different levels of kurtosis and skewness, another economy is chosen for the same economic parameters. This economy affords the following six equally probable outcomes: $45 \%$, $25 \%, 20 \%, 10 \%,-7 \%,-15 \%$. This distribution has a mean of $13.00 \%$ and a standard deviation of $21.95 \%$. The first step determines the implied coefficient of risk aversion which turns out to be 5.38753 . The second step identifies the premium, given the change in risk aversion of 0.06 . The premium is found to be 0.000341 or 3.41 basis point, lower than the previous one and represents $0.262 \%$ of the average return of a portfolio in common stocks.

Danthine and Donaldson (2015) report that the distribution of a portfolio of common stocks from January 1996 to December 2006 is represented by the following parameters: $0.57 \%$ as a monthly return and $4.5 \%$ as a monthly standard deviation. In annual terms these parameters are respectively $6.84 \%$, i.e. 0.57 x 12 , and $15.59 \%$, i.e. 4.5 $\mathrm{x} \sqrt{12}$.

We assume seven equally probable outcomes: $30 \%, 20 \%, 10 \%, 8 \%, 5 \%,-10 \%,-15 \%$. These outcomes define a probability distribution of mean $6.8571 \%$ and standard deviation $15.7314 \%$, quite close to the parameters in the preceding paragraph. The first step of the computation process produces an implied coefficient of risk aversion of 3.00969. The second step results in a premium of 0.000591 , or 5.91 basis points, and this premium corresponds to $0.862 \%$ of the mean of $6.8571 \%$.

Finally we assume the following seven equally probable outcomes: $30 \%, 20 \%, 10 \%, 5 \%, 0 \%,-8 \%,-9 \%$. These outcomes define a probability distribution of mean $6.8571 \%$ and standard deviation $14.3809 \%$, quite close to the parameters in the preceding two paragraphs. The first step of the computation process produces an implied coefficient of risk aversion of 3.99027. The second step results in a premium of 0.000408 , or 4.08 basis points, and this premium corresponds to $0.595 \%$ of the mean of $6.8571 \%$.

As a summary of this section we found that in the long run the additional required premium to the expected utility with the higher risk aversion varies between 3.41 basis points and 7.56 basis points. While these premiums are implied by a statistically significant additional change in risk aversion, there is no way to test whether these premiums are themselves statistically significant. One thing is sure these estimates are economically quite small.

\section{Conclusion}

We started by deriving the classic Euler equation of the Consumption Capital Asset Model (CCAPM). Then we assumed that the coefficient of risk aversion is different for the two contiguous time periods. This assumption allowed us to find a linear relation between the time-dependent risk-free rate and the log of real per capita consumption. By estimating this relation it appeared that there is continuum from the short run to the long run. In the short run risk aversion is lower by around -0.025 , and in the long run the risk aversion is higher by around 0.035 , making a change between the short run and the long run of 0.06 . Although these estimates are relatively small they are found to be statistically very significant. After that we went on to estimate the required additional premium for the long run that is implied by the change in risk aversion. This premium turns out to be also small averaging 5.24 basis points. However it was impossible to test whether this premium is statistically significant.

The evidence that risk aversion is different between the short run and the long run is strong. Nonetheless it is economically small. The long run is reached after around 4 years. The required additional premium to hold the risky asset because of the increase in risk aversion is also economically small, averaging 5.24 basis points. This paper tries to elucidate how much the data in the stock market provides information on varying preferences, and whether varying preferences can explain the term structure of market stock volatility. Lately an issue was brought forward on whether stock markets are more or less volatile in the long run (Siegel, 2008, 2014; Pástor \& Stambaugh, 2009, 2012). This paper contributes marginally to this important issue. Since our main conclusion is that risk aversion is higher in the long run, investors will be willing to accept less risk in the long run, unless they are compensated by a sufficiently higher return premium. The difference in risk aversion, while statistically quite significant, is economically small, which implies that the difference in risk aversion between the short run and the long run is also minimal, probably as minimal as the additional risk premium $\theta$ required to compensate for the additional risk aversion. One thing is sure the long run risk cannot be lower than the short run risk, because, if $\theta$ is considered to be a constant, the long run variance $(\tilde{r}+\theta)=\operatorname{variance}(\tilde{r})$ which is the short run variance. So, at the minimum, the risks are the same. If $\theta$ is a random variable then the long run variance $(\tilde{r}+$ $\theta)=\operatorname{variance}(\tilde{r})+\operatorname{variance}(\theta)+2 \operatorname{covariance}(\widetilde{r}, \theta)$. The long run variance, variance $(\tilde{r}+\theta)$, is still expected to be higher than the short run variance, variance $(\tilde{r})$, unless the covariance between $\tilde{r}$ and $\theta$ is sufficiently negative to neutralize the variance of $\theta$, which is unlikely. 


\section{References}

Azar, S. A. (2006). Measuring relative risk aversion. Applied Financial Economics Letters, 2(5), 341-345. https://doi.org/10.1080/17446540600690151

Azar, S. A. (2012). On the specification of the asset evolution equation in consumption models. Applied Economics Letters, 19(2), 113-116. https://doi.org/10.1080/13504851.2011.568387

Brigham, E. F., \& Houston, J. F. (2013). Fundamentals of Financial Management (13th ed.). South-Western

Campbell, J. Y., \& Viciera, L. M. (2002). Strategic Asset Allocation. Oxford, Oxford University Press. https://doi.org/10.1093/0198296940.001.0001

Danthine, J. P., \& Donaldson, J. B. (2015). Intermediate Financial Theory (3rd ed.). Amsterdam, Elsevier, Academic Press,

Dickey, D. A., \& Fuller, W. A. (1979). Distribution of the estimators for autoregressive time series with a unit root. Journal of the American Statistical Association, 74(366a), 427-431. https://doi.org/10.1080/01621459.1979.10482531

Dickey, D. A., \& Fuller, W. A. (1981). Likelihood ratio statistics for autoregressive time series with a unit root. Econometrica: Journal of the Econometric Society, 1057-1072. https://doi.org/10.2307/1912517

Elliott, G., Rothenberg, T. J., \& Stock, J. H. (1996). Efficient tests for an autoregressive unit root. Econometrica: Journal of the Econometric Society, 64(4), 813-836. https://doi.org/10.2307/2171846

EViews 9.5.(2016). HIS Global Inc., Irvine, California.

Hansen, B. E. (1992a). Efficient estimation and testing of cointegrating vectors in the presence of deterministic trends. Journal of Econometrics, 53, 87-121. https://doi.org/10.1016/0304-4076(92)90081-2

Hansen, B. E. (1992b). Tests for parameter instability in regressions with I(1) processes. Journal of Business and Economic Statistics, 10, 321-335. https://doi.org/10.1080/07350015.1992.10509908

Park, J. Y. (1992). Canonical cointegrating regressions. Econometrica: Journal of the Econometric Society, 60, 119-143. https://doi.org/10.2307/2951679

Pástor, L., \& Stambaugh, R. F. (2009). Predictive systems: Living with imperfect predictors. The Journal of Finance, 64(4), 1583-1628. https://doi.org/10.1111/j.1540-6261.2009.01474.x

Pástor, L., and Stambaugh, R. F. (2012). Are stocks really less volatile in the long run? The Journal of Finance, 67(2), 431-478. https://doi.org/10.1111/j.1540-6261.2012.01722.x

Pesaran, M. H., \& Shin, Y. (1999). An autoregressive distributed lag modelling approach to cointegration analysis. Econometrics and Economic Theory in the $20^{\text {th }}$ Century: The Ragnar Frisch Centennial Symposium, Cambridge University Press. https://doi.org/10.1017/CCOL521633230.011

Pesaran, M. H., Shin, Y., \& Smith, R. (2001). Bounds testing approaches to the analysis of level relationships. Journal of Applied Econometrics, 16, 289-326. https://doi.org/10.1002/jae.616

Phillips, P. C., \& Hansen, B. E. (1990). Statistical inference in instrumental variables regression with I(1) processes. Review of Economics Studies, 57, 99-125. https://doi.org/10.2307/2297545

Phillips, P. C., \& Perron, P. (1988). Testing for a unit root in time series regression. Biometrika, 75(2), 335-346. https://doi.org/10.1093/biomet/75.2.335

Ross, S. A., Westerfield, R. W., \& Jaffe, J. F. (2002). Corporate Finance (6th ed.). Boston, MA: McGraw-Hill,

Saikkonen, P. (1992). Estimation and testing of cointegrated systems by an autoregressive approximation. Econometric Theory, 8, 1-27. https://doi.org/10.1017/S0266466600010720

Siegel, J. J. (2008). Stocks for the Long Run: The Definitive Guide to Financial Market Returns and Long-Term Investment Strategies (4th ed.). New York: McGraw-Hill.

Siegel, J. J. (2014). Stocks for the Long Run: The Definitive Guide to Financial Market Returns and Long-Term Investment Strategies (5th ed.). New York: McGraw-Hill.

Stock, J. H., \& Watson, M. (1993). A simple estimator of cointegrating vectors in higher order integrated systems. Econometrica: Journal of the Econometric Society, 61, 783-820. https://doi.org/10.2307/2951763 


\section{Copyrights}

Copyright for this article is retained by the author(s), with first publication rights granted to the journal.

This is an open-access article distributed under the terms and conditions of the Creative Commons Attribution license (http://creativecommons.org/licenses/by/4.0/). 